\title{
Combined N-Acetylcysteine and Clomiphene Citrate for Ovulation Induction in Polycystic Ovary Syndrome, a Double Blind Randomized Controlled Trial
}

\author{
Hassan $\mathbf{M}^{1}$, Alalfy $\mathbf{M}^{2 *}$, Hassan $\mathbf{H}^{2}$ and Ogila $\mathrm{A}^{3}$ \\ ${ }^{1}$ Department of Obstetrics and Gynecology, Cairo \\ University, Egypt \\ ${ }^{2}$ Department of Reproductive Health and Family \\ Planning, National Research Centre and Consultant of \\ OB/ Gyn, Aljazeerah Hospital, Egypt \\ ${ }^{3}$ Department of Obstetrics and Gynecology, Cairo \\ University, Egypt \\ *Corresponding author: Mahmoud Alalfy, \\ Department of Reproductive Health and Family Planning, \\ National Research Centre and Consultant of OB/ Gyn, \\ Aljazeerah Hospital, Egypt
}

Received: March 18, 2019; Accepted: March 27, 2019; Published: April 03, 2019

\begin{abstract}
Background: Polycystic ovary syndrome is the commonest endocrinological disorder in women in child bearing period. The PCOS is more prevalent nowadays due to availability of diagnostic tools.
\end{abstract}

Aim: To evaluate the additive value of $\mathrm{N}$-Acetylcysteine (NAC) to Clomiphene Citrate (CC) on outcome of ovulation induction in women with PCOS.

Patients and Methods: A randomized controlled trial was conducted at Algezeera hospital and Almarwa hospital, Egypt, in the period from April 2018 till January 2019 on 150 infertile women.

Results: There was a statistically significant difference between the case and control group in pregnancy rate with better pregnancy rate in women received NAC together with $C C$ with a $P$ value $=0.008$ than control group who received $\mathrm{CC}$ alone.

Conclusion: NAC when added to CC can enhance ovulation and pregnancy rates in PCOS patients.

\section{Introduction}

Women that have polycystic ovary syndrome are more liable to have insulin resistance and obesity [1]. Some women who have PCOS are not obese but have hyperinsulinemia that hinder ovulation because hyperinsulinemia has a vital role in pathophysiology of PCOS through stimulation of secretion of androgen from theca cells of the ovary and inhibit sex hormone binding globulin formation leading to an increase in free androgens. Moreover, hyperinsulinemia changes the pulsatile production of FSH and LH Leading to impairment of ovulation [2]. Unexplained infertility is diagnosed when there are no definite factors that cause infertility [3]. Clomiphine citrate resistance is failure of ovulation after administration of $150 \mathrm{mg}$ of clomiphine citrate for five days in a cycle for at least three treatment cycles this occurs frequenly with obesity, insulin resistance and hyperandrogenemia [4]. N-Acetyl Cysteine (NAC) is the acetylated form of the amino acid L-cysteine. It is a source of sulfhydryl groups and is converted in vivo to metabolites that Enhance glutathione secretion, increase detoxification and act as an antioxidant [5].

\section{Patients and Methods}

This is a randomized controlled trial that was conducted at Algezeera hospital and Almarwa hospital, Egypt, on 150 infertile women with PCOS.

\section{Inclusion criteria}

Women who fulfilled the diagnostic criteria for PCOS, which includes 2 of the following 3 criteria, Hypergonadism, chronic oligomenorrhea or anovulation and polycystic ovarian echopattern [6].
All patients had patent both fallopian tubes confirmed by Hysterosalpingography (HSG). Males of the women included in the study had normal semen profile according to WHO criteria.

\section{Exclusion criteria}

Coexistence of other causes of infertility other than anovulatory cause, Thyroid dysfunction, Hyperprolactinemia, congenital adrenal hyperplasia, Cushings syndrome, D.M using medications that interfere with carbohydrate balance.

\section{Consent}

All ladies included in the research signed an informed written consent before participating into the study. All women were subjected to full history taking, Full examination, $2 \mathrm{D}$ transvaginal ultrasound on day 2 of the cycle, FSH, LH hormonal essay at day 2 of the cycle.

\section{Randomization}

Randomization of cases was done by computer method. 150 women with infertility and have PCOS were enrolled in the study and were distributed in two groups: group 1 and group 2. The randomization allocation was 1:1. The two groups are randomly selected.

\section{Allocation and Concealment}

150 opaque envelopes were numbered serially and in each envelope the corresponding letter which donate the allocated group was put according to randomization table then all envelops were closed and put in one box. When the first patient arrives the first envelope was opened and the women were allocated according to the letter inside.

Group 1 received CC $100 \mathrm{mg} / \mathrm{dl}$ plus NAC $1.2 \mathrm{~g} / \mathrm{d}$, NAC
Citation: Hassan M, Alalfy M, Hassan $\mathrm{H}$ and Ogila A. Combined N-Acetylcysteine and Clomiphene Citrate for Ovulation Induction in Polycystic Ovary Syndrome, a Double Blind Randomized Controlled Trial. Austin J Obstet Gynecol. 2019; 6(1): 1134. 
Table 1: Demonestrates a comparison between $\mathrm{CC}+\mathrm{NAC}$ and $\mathrm{CC}+$ placebo group as regarding demographic data.

\begin{tabular}{|l|c|c|c|}
\hline & CC+NAC Group (N=150) & CC +NAC group (N=150) & P value \\
\hline Age (years) Mean \pm SD & $26 \pm 5.2$ & $26.2 \pm 4.9$ & 0.732 \\
\hline Weight (KG) Mean \pm SD & $74.2 \pm 9.7$ & $74.9 \pm 9.1$ & 0.52 \\
\hline Height (cm) Range Mean \pm SD & $159.3 \pm 5.8$ & $160 \pm 6.2$ & NS \\
\hline BMI Range Mean \pm SD & $27.8 \pm 3.1$ & $28.1 \pm 3.2$ & NS \\
\hline
\end{tabular}

NS: Non Significant

Table 2: Demonestrates a comparison between $\mathrm{CC}+\mathrm{NAC}$ and $\mathrm{CC}+$ placebo as regarding FSH, $\mathrm{LH}$ and FSH/LH ratio.

\begin{tabular}{|l|c|c|c|}
\hline & CC+NAC Group (N=150) & CC + placebo group (N=150) & P value \\
\hline FSH/LH Mean \pm SD & $6.5 \pm 2.2$ & $6.6 \pm 2.1$ & 0.687 \\
\hline LH Mean \pm SD & $7.3 \pm 2.1$ & $7.2 \pm 2.3$ & 0.649 \\
\hline FSH / LH Mean \pm SD & $0.8 \pm 0.2$ & $0.8 \pm 0.3$ & NS \\
\hline
\end{tabular}

Table 3: Shows a comparison between $\mathrm{CC}+\mathrm{NAC}$ and $\mathrm{CC}+$ placebo group as regarding endometrial thickness, number of mature follicles and ovulation rate.

\begin{tabular}{|c|c|c|c|}
\hline & SC + NAC Group $(\mathrm{N}=150)$ & CC+ placebo Group (N=150) & P value \\
\hline Endometrial thickness Mean \pm SD & $5.7 \pm 1.4$ & $5.6 \pm 1.2$ \\
\hline Number of dominant & & 0.507 \\
\hline Follicles & $110(73.3)$ & $118(78.7)$ \\
\hline 0 & $20(13.3)$ & $16(10.7)$ \\
\hline 1 & $12(8)$ & $8(5.3)$ \\
\hline 2 & $8(5.3)$ & $8(5.3)$ \\
\hline 3 & $60(40 \%)$ & $36(24 \%)$ \\
\hline
\end{tabular}

Table 4: Comparison between NAC and control group as regard serum progesterone and serum E2.

\begin{tabular}{|c|c|c|c|c|}
\hline & $C C+N A C$ group $(N=150)$ & $\mathrm{CC}+$ placebo Group $(\mathrm{N}=150)$ & $P$ value & Significance \\
\hline Serum progesterone at midluteal phase Mean \pm SD & $6.7 \pm 5.2$ & $4.6 \pm 5.1$ & $<0.001$ & $\mathrm{~S}$ \\
\hline Serum E2 36 hours After HCG administration Mean \pm SD & $152.3 \pm 122.4$ & $112.4 \pm 121.8$ & 0.005 & $\mathrm{~S}$ \\
\hline
\end{tabular}

Was administered in the form of powder in a sachet that is diluted in a standard glass of water and administered twice per day while women in group 2, received CC plus a placebo which is an oral rehydration solution powder for five days beginning from day 3 of the cycle.

After that, on day 12 of the cycle, when there is a minimum of one follicle measures $\geq 18 \mathrm{~mm}$ by US, 10000 U HCG was given intramuscularly then timed intercourse was planned 36 hours post injection then B HCG level was measured 2 weeks after HCG injection.

\section{Outcome measures}

The primary outcome was to evaluate ovulation rate in the treatment cycles, While the secondary outcomes were, the number of mature follicles $\geq 18 \mathrm{~mm}$, serum E2 level at ovulation time, 36 hours post injection of HCG, pregnancy rate thickness of endometrium and progesterone concentration at midluteal time. Ongoing pregnancy was referred to as a living pregnancy at least twelve weeks post HCG administration.

\section{Results}

The present research was a double blinded randomized controlled trial that was made to assess the value of adding NAC as an adjuvant to $\mathrm{CC}$ on induction of ovulation in women with infertility with polycystic ovary syndrome.

The current study has the above mentioned inclusion and exclusion criteria.

We had 150 women who had infertility with PCOS who were randomly distributed into 2 groups.

There was no statistical significant difference between both groups regarding age with a mean $\pm \mathrm{SD}(27 \pm 5.7)$ in $\mathrm{CC}+\mathrm{NAC}$ group and $(25.9 \pm 5.9)$ in group 2 as demonstrated in Table 1.

Also the present study revealed that there is no statistical significant difference between the 2 groups regarding BMI, height and weight as shown in Table 1.

\section{Discussion}

In the present study, there was no statistically significant difference between both groups as regard age, weight, BMI, height, FSH, LH and FSH /LH ratio (Table 2).

Transvaginal US examination at day 12 of the cycle, revealed that there were mature folloicles more than $18 \mathrm{~mm}$ in about 48 women of the 150 women included in the study. Also there was a highly statistically significant difference in pregnancy rate As 28 women got 
Table 5: Shows a comparison between both CC+ NAC group and CC+ placebo as regard pregnancy.

\begin{tabular}{|c|c|c|c|}
\hline & CC+NAC Group $(\mathrm{N}=150)$ & CC+ placebo Group $(\mathrm{N}=150)$ & $\mathrm{P}$ value \\
\hline Pregnancy & $28(18.7 \%)$ & $12(8 \%)$ & 0.007 \\
\hline
\end{tabular}

Table 6: Demonestrates a comparison between $\mathrm{CC}+\mathrm{NAC}$ and $\mathrm{CC}+$ placebo group as regard multiple pregnancy and ovarian cyst.

\begin{tabular}{|c|c|c|c|}
\hline & CC+NAC Group (N=150) & CC+ placebo group (N=150) & S value \\
\hline Multiple pregnancy Twins & $4(2.7 \%)$ & $0(0 \%)$ & NS \\
\hline Adverse effects Ovarian cyst & $4(2.7 \%)$ & $0(0 \%)$ & NS \\
\hline
\end{tabular}

pregnant in CC+ NAC group whereas only 12 women got pregnant in the control group. A previous research made by salehpour et.al revealed that the ovulation and pregnancy rates were higher in the group who received the CC+ NAC versus the control group with statistically significant difference with a $\mathrm{P}$ value $<0.002$ and 0.04 respectively [7].

The present study is in agreement to a previous study made by salehpour et al., 2012, who performed a randomized controlled trial on 2 groups one received $\mathrm{CC}+\mathrm{NAC}$ and the other group received $\mathrm{CC}$ and placebo, they found that the mean endometrial thickness was statistically higher in CC+ NAC group with a P value $=0.001[8]$ (Table 3).

The present study results comes in accordance with a previous study made by badawy et al., who made a study on 537 women who had PCOS and concluded that NAC when added to CC showed significant increase in ovulation rate, serum progesterone and estrogen levels, endometrial thickness and pregnancy rate when compared to clomiphene citrate alone [5] (Table 4).

Also a previous study made by Rizk et al., revealed that NAC+ CC significantly enhanced the ovulation and pregnancy rates in 150 ladies with clomiphene citrate resistant PCOS women [9].

In the current study, the incidence of ovulation in the CC+ NAC group was 40 percent (36 cases out of 150 women) and in CC+ Placebo group was $24 \%$ (36 out of 150 women) with a statistically significant difference.

In the present study, the serum level of estradiol and progesterone were statistically significant difference between the 2 groups with a higher levels in the case group versus control group, with $\mathrm{P}$ values 0.005 and 0.001 respectively

In contrary to the results of our study, a previous research made by Abu Hashim et al., that concluded that combining metformin to CC has a higher efficacy than combining NAC and CC with better ovulation and pregnancy rates and also higher E2 and endometrial thickness [4] (Table 5,6). Where as a previous study made by Youssef et al., showed that there was no statistically significant difference between the group who used NAC and the group who did not receive it regarding pregnancy rates [10].

\section{Conclusion}

NAC when added to CC can enhance ovulation and pregnancy rates in PCOS patients.

\section{Acknowledgment}

Thanks to all staff members of IVF unit in Aljazeera Hospital and Almarwa hospital for their effort in this research.

\section{Disclosure Statement}

All authors declare that there are not any financial and personal relationships with other people or organizations that could inappropriately influence (bias) their work.

\section{ORCID}

Mahmoud Alalfy http://orcid.org/0000-0002-8429-6376.

\section{References}

1. Vrbikova J, Hainer V. Obesity and polycystic ovary syndrome. Obaases Facts. 2009; 2: 26-35.

2. John E Nestler. Metformin for the Treatment of the Polycystic Ovary Syndrome. N Engl J Med. 2008; 358: 47-54.

3. Alalfy M, Elgazzar A, Ghamry N, Elsawah H, Azkalani A, El Lithy A, et al. Physical endometrial manipulation and its impact on success rate and live birth rate in ICSI in patients with unexplained infertility after recurrent ICSI failure, a double blinded randomized controlled trial. J Matern Fetal Neonatal Med. 2019: 1-7.

4. Hashim HA, Rakhawy ME, Elaal IA. Randomized comparison of superovulation with letrozole vs. clomiphene citrate in an IUI program for women with recently surgically treated minimal to mild endometriosis. Acta Obstet Gynecol Scand. 2012; 91: 338-345.

5. Badawy A, State O, Abdelgawad S. N-Acetyl cysteine and clomiphene citrate for induction of ovulation in polycystic ovary syndrome: a cross over trial. Acta Obstet Gynecol Scand. 2007; 86: 218-222.

6. Rotterdam ESHRE/ASRM. Sponsored PCOS consensus workshop group, revised 2003 consensus on diagnostic criteria and long-term health risks related to Polycystic Ovary Syndrome (PCOS). Hum Reprod. 2004; 19: 441473.

7. Salehpour S, Tohidi M, Akhound MR, Amirzargar N. N-Acetyl cysteine, A novel remedy for plycystic ovarian syndrome. Int J fertile steril. 2009; 3: 6673.

8. Salehpour S, Akbari AS, Saharkhiz N, Sohrabi M, Moghimian F. N-Acetyl cysteine as an adjuvant to clomiphene citrate for successful induction of ovulation in infertile patients with polycystic ovary syndrome. J Obstet Gynecol Res. 2012; 38: 1182-1186.

9. Rizk AY, Bedaiwy MA, Al-Inany HG. N-Acetylcysteine is a novel adjuvant to clomiphene citrate resistant patients with polycystic ovary syndrome. Ferti steril. 2005; 83: 367-370.

10. Youssef G, Meguid AA, Alaa N, Makin B, Waly M, Abousetta A. N AAcetyl cysteine in anovulatory women: The impact of postcoital test. Middle East Fertil Soc J. 2006; 11: 109-112. 